\title{
Cytogenetic features in myelodysplastic syndromes
}

\author{
Detlef Haase
}

Received: 6 March 2008 / Accepted: 6 March 2008 / Published online: 15 April 2008

(C) The Author(s) 2008

\begin{abstract}
Myelodysplastic syndromes (MDS) comprise a group of bone marrow diseases characterized by profound heterogeneity in morphologic presentation, clinical course, and cytogenetic features. Roughly $50 \%$ of patients display clonal chromosome abnormalities. In several multicentric studies, the karyotype turned out to be one of the most important prognostic parameters and was incorporated into statistical models aiming for a better prediction of the individual prognosis like the International Prognostic Scoring System. However, due to the profound cytogenetic heterogeneity, the impact of many rare abnormalities as well as combinations of anomalies occurring in a substantial portion of patients with MDS is still unknown and can only be delineated on the basis of large international multicentric cooperations. Recently, the German-Austrian MDS Study Group presented cytogenetic findings in 2,072 patients with MDS, which serve as a basis for the characterization of the cytogenetic subgroups discussed in this article. The availability of new therapeutic options for low- and high-risk MDS targeted against distinct entities characterized by specific chromosome abnormalities, like 5q-deletions, monosomy 7, and complex abnormalities underlines the important role of cytogenetics for the clinical management of MDS. This article thus focuses on the clinical and prognostic relevance, the molecular background, and therapeutic perspectives in these three cytogenetic subgroups.
\end{abstract}

Keywords MDS - cytogenetics · karyotype - prognosis . $5 q^{-} \cdot$ monosomy $7 \cdot$ Complex abnormalities

D. Haase $(\bowtie)$

Department of Hematology and Oncology,

Georg-August-University,

Robert-Koch-Str. 40,

37075 Göttingen, Germany

e-mail: haase.onkologie@med.uni-goettingen.de

\section{Introduction}

The profound heterogenetity of myelodysplastic syndromes (MDS) is well-known from morphological and clinical studies, which finally lead to the establishment of classification, and prognostic scoring systems. It is becoming increasingly obvious that this heterogeneity also manifests itself against the background of genetic heterogeneity of MDS. In sharp contrast to the situation in chronic myeloid leukemia (CML) where one single cytogenetic abnormality, the translocation $\mathrm{t}(9 ; 22)(\mathrm{q} 34 ; \mathrm{q} 11)$, is the genetic hallmark of the disease, there is an enormous variability of cytogenetic abnormalities in MDS hampering not only the prognostic classification but also the delineation of the molecular background of cytogenetic aberrations in MDS. As an example in our recent multicentric cytogenetic analysis of patients with MDS, we observed 684 different types of chromosome abnormalities in a cohort of 1,080 patients with MDS and an abnormal karyotype [1].

\section{The cytogenetic profile of MDS}

In general, MDS show a characteristic genetic profile with an overweighing of unbalanced abnormalities. Most frequently, a loss of genetic material in the form of deletions and monosomies can be observed. A gain of genetic material with the appearance of total or partial trisomies is less frequent. Loss or gain of genetic material can also be the result of unbalanced translocations, which are frequently observed in MDS with multiple abnormalities. Taken together, it is thus obvious to assume that a prime molecular mechanism in MDS is the loss or inactivation of tumor suppressor genes, while the activation of oncogenes seems to be less relevant in myelodysplasia. 
In contrast to AML, balanced structural abnormalities like translocations and inversions are rare in MDS. Due to the profound genetic heterogeneity, the knowledge about distinct cytogenetic alterations was mainly restricted to the most frequent abnormalities $\left(-5 / 5 \mathrm{q}^{-},-7 / 7 \mathrm{q}^{-},+8,20 \mathrm{q}-\right.$, and $-\mathrm{Y})$, although, in MDS, rare chromosome abnormalities are present in a substantial portion of patients. In a recent analysis of the German-Austrian MDS Study Group, 59\% of all 2,370 abnormalities observed in 1,080 patients with MDS where rare; that is, they occurred with a frequency of less than $2 \%$ [1]. In this situation, prognostic knowledge can only be deepened by large-scale multicentric studies with a high enough number of abnormal cases with follow-up data. This development was initiated by the International MDS Risk Assessment Working Group (IMRAW) ending up with the establishment of the International Prognostic Scoring System (IPSS), which was based upon the analysis of 816 patients with de novo MDS of whom 327 had abnormal karyotypes [2]. A next step forward was the study of the Spanish cooperative group with 500 abnormal cases [3] followed by our German-Austrian dataset with 1,080 patients with chromosome abnormalities [1]. The situation is furthermore complicated by the fact that chromosome abnormalities in principle can occur in three different conditions: as isolated abnormality, together with one additional change, and as part of complex abnormalities with at least two additional cytogenetic alterations. Table 1 shows the incidence of the 21 most frequent abnormalities according to the number of accompanying alterations occurring in our German-Austrian patient cohort.

\section{Cytogenetic prognosis}

The first large-scale cytogenetic studies in patients with MDS encompassing more than 100 patients where published more than 20 years ago [4-7]. In the following years, the patients cohorts increased step by step from nearly 250 patients [8] to some 400 patients [9, 10]. In 1997, Greenberg published a collaborative multicentric international data set of more than 800 patients with de novo MDS, which was the basis for the establishment of the IPSS [2]. This database was further surmounted by the analyses of the Spanish cooperative group with 968 patients examined (Table 2), which represented the largest number of patients with MDS karyotyped so far [3]. Recently, the German-Austrian Study Group published their multicentric analyses of more than 2,100 patients with MDS [1].

What has changed and what has been achieved during these last 25 years of cytogenetic analyses in MDS? If the aberration rate is considered, there is a gradual increase in the portion of abnormal cases from under $40 \%$ in the most earlier studies to $50 \%$ in the more recent analyses of Toyama, Solé, and Haase $[1,3,10]$. Although the composition of the patient cohorts may play a role for the portion of clonal abnormalities in a given collective, other factors like the improvement of culture conditions possibly due to the use of recombinant myeloid growth factors [11] might have contributed to the increase in the aberration rate in cytogenetic studies. To date, an aberration rate of $50 \%$ can be regarded as an international standard.
Table 1 Incidence of chromosome abnormalities in MDS related to 2,072 patients examined successfully

${ }^{a}$ Of cases with the respective abnormality

\begin{tabular}{lcccc}
\hline Anomaly & $\begin{array}{l}\text { total, } \\
n(\% \text { of all cases })\end{array}$ & Isolated, $n\left(\%^{\mathrm{a}}\right)$ & $\begin{array}{c}\text { With one additional } \\
\text { abnormality, } n\left(\%^{\mathrm{a}}\right)\end{array}$ & $\begin{array}{c}\text { As part of complex } \\
\text { abnormalities, } n\left(\%^{\mathrm{a}}\right)\end{array}$ \\
\hline $5 \mathrm{q}-$ & $312(15.1)$ & $146(47)$ & $52(17)$ & $114(36)$ \\
$-7 / 7 \mathrm{q}-$ & $230(11.1)$ & $86(37.5)$ & $31(13.5)$ & $113(49)$ \\
+8 & $173(8.4)$ & $81(46.8)$ & $37(21.4)$ & $55(31.8)$ \\
$-18 / 18 \mathrm{q}-$ & $78(3.8)$ & $3(3.8)$ & $2(2.6)$ & $73(93.6)$ \\
$20 \mathrm{q}-$ & $74(3.6)$ & $36(48.6)$ & $10(13.5)$ & $28(37.8)$ \\
-5 & $69(3.3)$ & $1(1.4)$ & $4(5.8)$ & $64(92.8)$ \\
$-\mathrm{Y}$ & $58(2.8)$ & $41(70.7)$ & $5(8.6)$ & $12(20.7)$ \\
+21 & $45(2.2)$ & $5(11.1)$ & $18(40)$ & $22(48.9)$ \\
$-17 / 17 \mathrm{p}-$ & $42(2.0)$ & $1(2.4)$ & $1(2.4)$ & $40(95.2)$ \\
inv/t(3q) & $41(2.0)$ & $16(39)$ & $8(19.5)$ & $29(71.5)$ \\
$-13 / 13 \mathrm{q}-$ & $40(1.9)$ & $5(12.5)$ & $6(15)$ & $28(75.7)$ \\
$+1 /+1 \mathrm{q}$ & $37(1.8)$ & $3(8.1)$ & $6(16.2)$ & $26(78.8)$ \\
-21 & $33(1.6)$ & $3(9.1)$ & $4(12.1)$ & $18(64.3)$ \\
+11 & $28(1.4)$ & $6(21.4)$ & $4(14.3)$ & $24(92.3)$ \\
-12 & $26(1.3)$ & 0 & $2(7.7)$ & $12(48)$ \\
$12 \mathrm{p}-$ & $25(1.2)$ & $7(28)$ & $6(24)$ & $15(62.5)$ \\
$\mathrm{t}(5 \mathrm{q})$ & $24(1.2)$ & $6(25)$ & $3(12.5)$ & $11(47.8)$ \\
$11 \mathrm{q}-$ & $23(1.1)$ & $8(34.8)$ & $4(17.4)$ & $12(52.2)$ \\
$9 \mathrm{q}-$ & $23(1.1)$ & $8(34.8)$ & $3(13)$ & $22(100)$ \\
$\mathrm{t}(7 \mathrm{q})$ & $22(1.1)$ & $6(27.3)$ & $6(27.3)$ & \\
-20 & $22(1.1)$ & 0 & 0 & \\
\hline & & & & \\
\hline
\end{tabular}




\section{Prognostic relevance of chromosome abnormalities}

The prognostication of patients with MDS has become an important means for the development of therapeutic strategies based on more individualized risk assessment. Even in the most recent prognostic scoring system, the World Health Organization classification-based Prognostic Scoring System, cytogenetics play a decisive role [12]. In general, three to four prognostic cytogenetic categories can be distinguished. In several multicentric investigations, cytogenetics have been proven to be highly relevant independent prognostic parameters $([2,3,13]$, see also Table 2$)$.

\section{Good prognosis}

Even in the earliest study considered here, Knapp et al. [4] described the prognostic relevance of cytogenetic findings with a normal karyotype as favorable and complex abnormalities as being associated with bad prognosis. The good prognosis of a normal karyotype was confirmed by nearly all other groups. Thus, in contrary to the situation in AML where patients with a normal karyotype have an intermediate outcome and prognosis is significantly influenced by additional molecular alterations, in MDS, a normal karyotype is undisputedly associated with good prognosis. Further, well-established abnormalities defining good-risk subgroups are deletions of $5 q$ and $20 q$ as well as loss of the Y-chromosome, although the question whether this latter abnormality is age related, or a real clonal marker is unsolved as yet. The Spanish group identified further new cytogenetic abnormalities with a good prognosis (12p- and 11q-) [3].
In the German-Austrian multicentric study, the following abnormalities were associated with a favorable clinical course with a median survival between more than 9 years and 32 months: normal karyotype, $\mathrm{t}(1 \mathrm{q}), 5 \mathrm{q}^{-}, \mathrm{t}(7 \mathrm{q}), 9 \mathrm{p}^{-}$, $12 \mathrm{q}-, \mathrm{t}(15 \mathrm{q}), \mathrm{t}(17 \mathrm{q}), 20 \mathrm{q}-,+21,-21,-\mathrm{X},-\mathrm{Y}$. However, prognosis was only favorable when not more than one additional abnormality was present [1].

\section{Intermediate prognosis}

In most studies, patients with trisomy 8 displayed an intermediate clinical course. Until the Spanish group published their results on more than 980 patients, the knowledge of cytogenetic findings with an intermediate prognosis was very limited. In the IPSS, all abnormalities neither belonging to the good-risk group (isolated $5 \mathrm{q}-$, $20 \mathrm{q}^{-}$, and loss of Y-chromosome) nor to the bad risk cohort (complex [greater than or equal to three abnormalities] or any chromosome 7 abnormality) were designated to be of intermediate prognosis not by availability of survival data but by definition [2]. In their large Spanish dataset, Solé et al. delineated new abnormalities associated with an intermediate clinical course (3q abnormalities, trisomy 9, 11q translocations, and $17 \mathrm{p}$ deletions) [3]. The results of White et al. [14] and Toyama et al. [10] who identified $-7 / 7 \mathrm{q}-$ and $12 \mathrm{p}-$ and trisomy 21 , respectively, as abnormalities with an intermediate prognosis were not confirmed by other groups. Recently, the multicentric database of the German-Austrian MDS Study Group revealed several infrequent abnormalities with an intermediate prognosis. A median survival time of $23-26$ months was observed in

Table 2 Cytogenetic prognostic findings in publications with greater than 100 patients examined

\begin{tabular}{|c|c|c|c|c|c|}
\hline Author, year & $\begin{array}{l}\text { Number } \\
\text { of patients }\end{array}$ & Abnormal (\%) & Favorable & Intermediate & Unfavorable \\
\hline Knapp 1985 & 174 & $66(38)$ & Normal (NN) & & Complex \\
\hline Nowell 1986-1989 & 144 & $63(44)$ & $5 q^{-}, 20 q^{-}$ & +8 & $-7 / 7 \mathrm{q}^{-}$ \\
\hline Billström 1988 & 169 & $74(44)$ & $\mathrm{NN}, 5 \mathrm{q}^{-}$ & +8 & $-7 / 7 \mathrm{q}-$ \\
\hline Pierre 1989 & 247 & $106(43)$ & $\mathrm{NN}$ & & Complex \\
\hline Morel 1993 & 408 & $151(37)$ & $\begin{array}{l}\mathrm{NN}, 5 \mathrm{q}^{-},-\mathrm{Y},-7 / 7 \mathrm{q}^{-} \\
20 \mathrm{q}^{-}\end{array}$ & +8 & Complex \\
\hline Toyama 1993 & 401 & $200(50)$ & +8 & $-7 / 7 q-$ & Complex \\
\hline White 1994 & 198 & $75(38)$ & $\mathrm{NN}, 5 \mathrm{q}^{-}$ & $12 \mathrm{p}^{-},+21$ & Complex, $+8,20 \mathrm{q}^{-}$ \\
\hline Greenberg 1997 & 816 & $327(40)$ & $\mathrm{NN}, 5 \mathrm{q}^{-}, 20 \mathrm{q}^{-},-\mathrm{Y}$ & All others & $\begin{array}{l}\text { Complex, } \\
\text { abnormal \#7 }\end{array}$ \\
\hline Solé 2005 & 968 & $500(51)$ & $\begin{array}{l}\mathrm{NN}, 5 \mathrm{q}^{-}, 20 \mathrm{q}^{-} \\
-\mathrm{Y}, 11 \mathrm{q}^{-}, 12 \mathrm{p}^{-}\end{array}$ & $\begin{array}{l}\text { rea } 3 \mathrm{q},+8,+9 \\
\text { t11q, } 17 \mathrm{p}^{-}\end{array}$ & $\begin{array}{l}\text { Complex, }-7 / 7 \mathrm{q}^{-}, \\
\text {i17q }\end{array}$ \\
\hline Haase 2007 & 2,072 & $1,080(51)$ & $\begin{array}{l}\mathrm{NN},+1 /+1 \mathrm{q}, \mathrm{t}(1 \mathrm{q}), 5 \mathrm{q}- \\
\mathrm{t}(7 \mathrm{q}), 9 \mathrm{q}-, 12 \mathrm{p}- \\
\text { abnormal } \# 15, \mathrm{t}(17 \mathrm{q}) \\
20 \mathrm{q}-,-21,+21,-X,-\mathrm{Y}\end{array}$ & $\begin{array}{l}\text { rea } 3 \mathrm{q},-7,7 \mathrm{q}^{-}, \\
+8,11 \mathrm{q}-, \mathrm{t}(11 \mathrm{q} 23), \\
+19, \text { complex }(=3)\end{array}$ & Complex $(>3), \mathrm{t}(5 \mathrm{q})$ \\
\hline
\end{tabular}

rea Rearranged 
patients with trisomy 8 and 11q- (called Intermediate-I). A more worse prognosis with a median survival time between 20 and 14 months was found for 11q23 translocations, chromosome $3 \mathrm{q}$ aberrations, trisomy $19, \mathrm{qq}$ deletions, and complex abnormalities with three different chromosomal alterations and monosomy 7 (called Intermediate-II) [15].

\section{Poor prognosis}

There is a great consensus in all publications on cytogenetic prognosis in MDS that complex abnormalities characterize a MDS subgroup with bad prognosis and a median survival time significantly below 1 year, although the threshold at which the number of abnormalities confers bad prognosis is a matter of debate. While in most publications, the term "complex" is used for three or more abnormalities, in the Medical Research Council AML trials, bad prognosis was assigned to cases with five or more abnormalities [16]. Recently, we clearly could show that, in patients with MDS, median survival is significantly reduced only when more than three abnormalities are present, reducing the median survival from 17 months in cases with three abnormalities to less than 9 months in cases with four or more anomalies [1]. Besides complex changes, partial and total monosomy 7 was ranked to the cytogenetic findings with an unfavorable clinical course [3, 5-7]. Within the IPSS, any chromosome 7 abnormality was counted to the bad prognostic findings [2]. As mentioned above, in the German-Austrian dataset, $-7 / 7 \mathrm{q}-$ showed a significant better prognosis (14 and 19 months median survival time, respectively) as compared to the complex abnormality group defined by four or more chromosomal changes (8.7 months) and was thus attributed to the intermediate-II group [15]. The findings of Toyama et al. [10] who observed an unfavorable course in patients with trisomy 8 or 20q deletions was not confirmed by any other group. Solé et al. described a median survival of under 12 months in ten patients with an isochromosome of 17q [3]. Since, in the German-Austrian dataset, this abnormality was too infrequent for a statistically meaningful analysis, the Spanish findings are convincing but still need further confirmation.

\section{Prognostic scoring}

In the IPSS, three different cytogenetic subgroups were established and weighted against bone marrow blast counts and cytopenias by multivariate analysis [2]. Applying the cytogenetic part of the IPSS to our German-Austrian dataset, $59 \%$ of the patients had a good risk karyotype (normal, isolated $5 \mathrm{q}^{-}, 20 \mathrm{q}-$, or loss of Y-chromosome) with a median survival of 54 months, $19 \%$ of the collective had an intermediate prognosis (neither good risk nor bad risk cytogenetics) with a median survival of 31 months, and $22 \%$ displayed a dismal prognosis (any chromosome 7 anomaly, complex $[\geq 3]$ changes) with a median survival of 11 months [1].

The application of the new cytogenetic findings derived from the German-Austrian dataset allows the definition of four different cytogenetic prognostic subgroups (Table 3 and Fig. 1). The low-risk group covers $73 \%$ of patients with 14 cytogenetic categories and a median survival of 55 months, the intermediate groups I and II (15.5\% of patients) with eight cytogenetic categories and a median survival of 29 (intermediate-I) and 15 months (intermediate-II), and the high-risk group (11.5\% of patients) with a median survival of 8 months [15]. In comparison to the IPSS, our new cytogenetic prognostication splits the intermediate group into two distinctly separate subgroups with significantly different median survival. The bad-risk group is more strictly defined with a lower median survival time ( 8 vs. 11 months). While the IPSS assigned an intermediate risk by exclusion and not by knowledge, our intermediate cytogenetic subgroup was based exclusively on available survival data of patients treated with supportive care only thus reflecting the natural course of the disease. Taking into account only those patients with a known prognosis (in IPSS only good- and bad-risk patients), $81 \%$ of our patients could be categorized by the IPSS in comparison to $93 \%$ by the German-Austrian prognostic system.

A further element of the IPSS, the weighting of cytogenetics in comparison to other relevant parameters like the bone marrow blast counts, has become questionable. According to the IPSS, 0 scoring points are attributed to good-risk cytogenetics and blasts less than 5\%, intermediate cytogenetics as well as $5-10 \%$ blasts get 0.5 scoring points, and bad-risk cytogenetic findings are scored with 1.0. Eleven to $20 \%$ blasts are scored with 1.5 and $21-30 \%$ blasts with 2.0 points. Thus, bad-risk cytogenetics with a median survival of 11 months get less scoring points than patients with $11-20 \%$ blasts and a median survival in our cohort of 16.5 months. According to our observations, only patients with $21-30 \%$ blasts (11.7 months median survival) had a prognosis comparable to patients with bad-risk cytogenetics. Thus in a revision of the IPSS the weight of bad-risk cytogenetics has to be readjusted [17].

\section{Delineation of the most relevant cytogenetic subgroups 5q-, monosomy 7 , and complex abnormalities}

$5 q$ deletions

Deletions within the long arm of chromosome 5 are the most frequent cytogenetic changes in MDS accounting for 
Table 3 New cytogenetic prognostic subgroups of the German-Austrian MDS Study Group in 1,202 patients treated with supportive care only

\begin{tabular}{|c|c|c|c|}
\hline Cytogenetic risk & Cytogenetic finding & Number $(\%)$ & $\begin{array}{l}\text { Median surviva } \\
\text { (months) }\end{array}$ \\
\hline \multirow[t]{14}{*}{$\overline{\text { Good }}$} & $12 p^{-}$ & $7(0.6)$ & n.r. \\
\hline & $9 q^{-}$ & $6(0.5)$ & n.r. \\
\hline & $\mathrm{t}(15 \mathrm{q})$ & $6(0.5)$ & n.r. \\
\hline & $15 q^{-}$ & $5(0.4)$ & n.r. \\
\hline & +21 & $13(1.1)$ & 100.8 \\
\hline & $5 q^{-}$ & $132(11)$ & 77.2 \\
\hline & $20 \mathrm{q}-$ & $24(2)$ & 71.0 \\
\hline & $-\mathrm{X}$ & $6(0.5)$ & 56.4 \\
\hline & normal karyotype & $622(51.7)$ & 53.4 \\
\hline & $-\mathrm{Y}$ & $33(2.8)$ & 39.4 \\
\hline & $\mathrm{t}(1 \mathrm{q})$ & $7(0.6)$ & 34.7 \\
\hline & $\mathrm{t}(7 \mathrm{q})$ & $7(0.6)$ & 34.7 \\
\hline & $\mathrm{t}(17 \mathrm{q})$ & $6(0.5)$ & 32.1 \\
\hline & -21 & $6(0.5)$ & 32.0 \\
\hline \multirow[t]{2}{*}{ Intermediate-I } & $11 \mathrm{q}^{-}$ & $11(0.9)$ & 26.1 \\
\hline & +8 & $64(5.3)$ & 23.0 \\
\hline \multirow{6}{*}{ Intermediate-II } & $\mathrm{t}(11 \mathrm{q} 23)$ & $6(0.5)$ & 20.0 \\
\hline & Any $3 q$ abnormality & $16(1.3)$ & 19.9 \\
\hline & +19 & $5(0.4)$ & 19.8 \\
\hline & $7 q^{-}$ & $11(0.9)$ & 19.0 \\
\hline & Complex ( $=3$ anomalies) & $32(2.7)$ & 17.0 \\
\hline & -7 & $42(3.5)$ & 14.0 \\
\hline \multirow[t]{2}{*}{ Poor } & Complex ( $>3$ anomalies) & $134(11.1)$ & 8.7 \\
\hline & $\mathrm{t}(5 \mathrm{q})$ & $7(0.6)$ & 4.4 \\
\hline
\end{tabular}

n.r. Median survival not reached

molecular background of these abnormalities is increasing. It is generally accepted that not the illegitimate fusion of deoxyribonucleic acid (DNA) sequences at the variable

breakpoints of the deletions but loss of genetic information

Fig. 1 Kaplan-Meier survival curves according to the cytogenetic prognostic classification of the German-Austrian MDS Study Group. Log-rank test: $p<$ 0.0001 (3 degrees of freedom) [15]

roughly $30 \%$ of abnormal cases $[1,2,3]$. The deletions can have variable size; however, the common deleted region always spans the chromosome band $5 \mathrm{q} 31$. Due to intensive research during the last decade, our knowledge of the

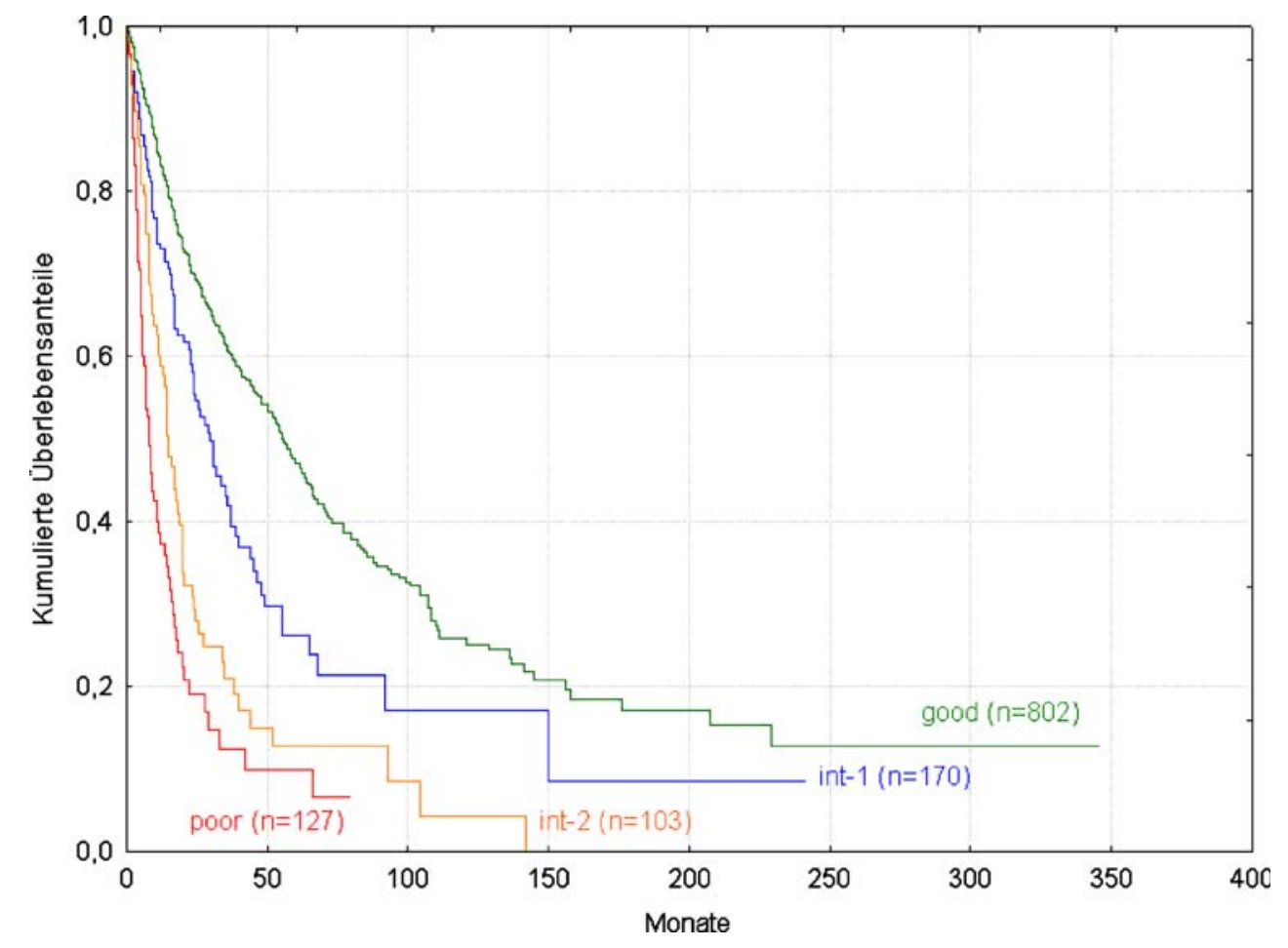


represents the relevant pathomechanism. There could be two different deleted regions in $5 \mathrm{q} 31$. One that is located more centromeric is possibly associated with bad prognosis, complex abnormalities, and high-risk, as well as therapyrelated, MDS. A second area is located more telomeric in the vicinity of band $5 \mathrm{q} 32$ and is supposed to be related to the good-risk 5q- syndrome [18-21. Recently, it has been convincingly shown by the means of sophisticated systematic knockout experiments on 41 candidate genes in the critical $5 \mathrm{q}-$ region that the gene for a ribosomal subunit protein, RPS41, seems to be a relevant gene in patients with $5 q-$ syndrome on the basis of haploinsufficiency [22]. The $5 \mathrm{q}-$ syndrome has been first described by Van den Berghe in 1974 [23]. It is cytogenetically characterized by an isolated deletion of chromosome 5q. A female preponderance is well documented. The clinical appearance is characterized by a refractory macrocytic anemia, normal or elevated platelets, and mild leukocytopenia. The clinical course is mild and long lasting with a very low risk for leukemic transformation. The bone marrow smears reveal less than 5\% blasts, while dysplasia of the erythroid and granulocytic lineages usually are discrete or even absent. Megakaryopoesis shows profound and characteristic dysplasias with either separated multiple nuclei, hypolobulation, microkaryocytes, and most characteristically monolobulated megakaryocytes with a round nucleus.

The prognosis of $5 \mathrm{q}$ deletions in MDS is generally favorable if they are not part of complex abnormalities; however, it is significantly modified by single additional cytogenetic changes $[1,24]$. Figure 2 shows the KaplanMeier survival curves for patients treated with supportive care only with isolated $5 \mathrm{q}^{-}, 5 \mathrm{q}-$ plus one additional abnormality, and $5 \mathrm{q}^{-}$as part of complex abnormalities derived from the German-Austrian database [1].

It is evident that additional abnormalities negatively influence survival in patients with $5 \mathrm{q}$ deletions. However, due to cytogenetic heterogeneity, the additive prognostic impact of distinct single additional abnormalities remains obscure as yet (Table 4).

Over a long period, the therapeutic standard in patients with noncomplex 5q deletions was supportive care only. In clinical trials, retinoic acid turned out to be inefficient, and low-dose cytarabine was more effective but led to a pronounced increase in severe neutropenic infections [25]. A preferential response to other modern therapeutic strategies like immunosuppression and suppression of DNA methyltransferase or histone deacetylase was not reported as yet. However, recently, List et al. reported a remarkably high response rate to the immunomodulating agent lenalidomide, which was especially pronounced in MDS patients with $5 \mathrm{q}$ deletions. Nine out of 12 patients with a $5 \mathrm{q}$ deletion displayed complete cytogenetic remissions, and 10 out of 12 experienced an erythroid response
[26]. Thus, a new promising agent may target cell clones in MDS bearing $5 \mathrm{q}$ deletions. These results could recently be confirmed on the basis of a large muliticentric trial [27].

\section{Monosomy 7}

Monosomy 7 is the second most frequent distinct chromosome abnormality in MDS occurring in some $25 \%$ of abnormal cases. It can present as total or partial monosomy. In the latter case, variable deletions of parts of the long arm lead to loss of genetic material of different size. As yet, no significant differences concerning the prognostic relevance have been observed between total and partial monosomy 7 . In the German-Austrian dataset, $36 \%$ of monosomy 7 were isolated ones, $14 \%$ displayed one additional abnormality, and $50 \%$ occurred as part of complex abnormalities [1]. Comparable to the situation in $5 \mathrm{q}$, also in $7 \mathrm{q}$, at least two and maybe more distinct regions of common deletions have been identified: the band $7 \mathrm{q} 22$ and the more telomeric regions $7 \mathrm{q} 31-32$ and $7 \mathrm{q} 36$. It is interesting to note that interstitial as well as terminal deletions might be due to cryptic unbalanced translocations. In single individuals, more than one different deletion has been found in one and the same patient, either within the same copy of chromosome 7 with retention of sequences between the deleted regions or within different cell clones [28, 29]. These observations clearly underline the regional genetic instability of the long arm of chromosome 7 , which makes this region especially prone to deletions of different size and localization as well as to structural abnormalities. On the other hand, it can be assumed that there must be a cluster of genes with tumor-suppressive features distributed over several chromosome bands in $7 \mathrm{q}$ with the same or very similar consequences when being inactivated by chromosomal abnormalities.

However, in contrast to some presumptions in the $5 \mathrm{q}$ deletions, as yet, no prognostic differences have been elaborated between different regions of deletions (reviewed in [20]). Investigations of the molecular background of monosomy 7 MDS are on the way. An association of this cytogentic subgroup with RAS mutations, mutations of AML1, and hypermethylation of p15INK4B have been reported [30, 31]. In an analysis of gene expression profiles in CD34+ cells from MDS patients with monosomy 7, a malignant phenotype with highly proliferative potential was found with an overexpression of HOX9A, PRAME, BMI-1, PLAB, and the DNA repair gene BRCA2. Parallelly, downregulation of the tumor suppressor gene p21, GATA2, and MAP was observed [32]. Clinically, monosomy 7 is characterized by a lower median age of the affected patients as compared to $5 \mathrm{q}$ deletions, severe refractory cytopenias, and a proneness to life-threatening infections. Predisposing 
Survival (Kaplan-Meier) of patients with $5 q-$

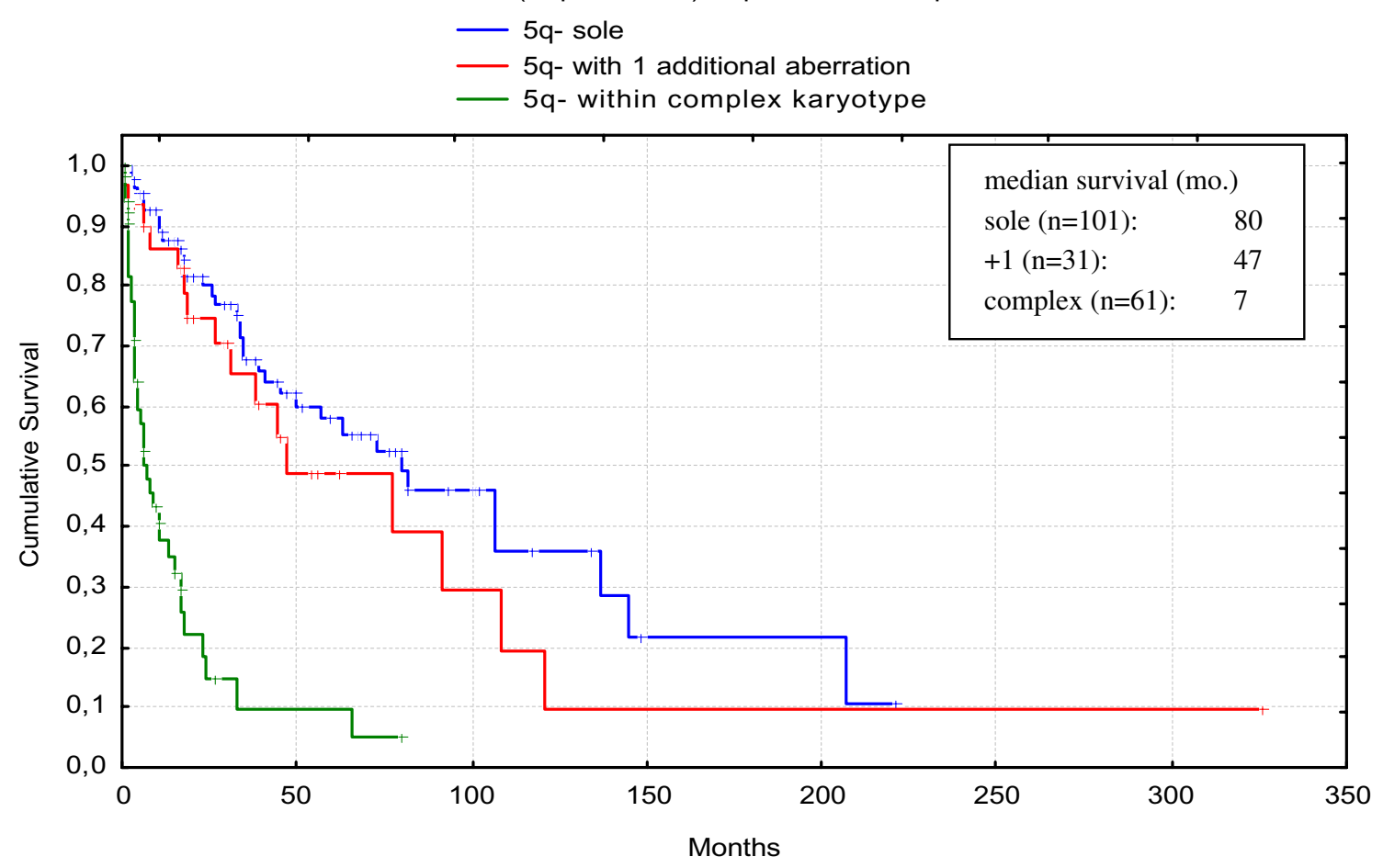

Fig. 2 Median survival according to accompanying abnormalities in patients with 5q deletions. Log-rank test: $p \leq 0.0001$ ( 2 degrees of freedom), $p=0.30$ (isolated vs. +1 ), $p \leq 0.0001$ (isolated vs. complex), $p=0.0001$ ( +1 vs. complex)

conditions recurrently observed in cases with monosomy 7 are antecedent aplastic anemia, Fanconi's anemia, neurofibromatosis type I, cyclic neutropenia, and long-term treatment with granulocyte colony-stimulating factor (GCSF), as well as Schwachman's syndrome. It is of special interest that myeloid cells harboring monosomy 7 seem to be preferentially responsive to a stimulation by myeloid growth factors like G-CSF and granulocyte-macrophage CSF in vitro [33, 34] as well as in vivo [35]. Although being obvious, this phenomenon never was exploited therapeutically for a targeted priming strategy for patients with monosomy 7 .

In extremely rare cases, for the so-called monosomy 7 syndromes, the abnormality has a familiar background. In a substantial portion of patients, a mutagen exposition (benzene, solvents, irradiation, or radio- and/or chemotherapy) was documented.

In contrast to the situation in $5 \mathrm{q}$ deletions, in monosomy 7, additional abnormalities do not have such a profound impact on outcome as seen in $5 \mathrm{q}$ deletions, since

Table 4 Frequencies (in percent of all cases with the respective primary abnormality) of accompanying abnormalities

\begin{tabular}{|c|c|c|c|c|c|}
\hline \multicolumn{2}{|l|}{$5 \mathrm{q}-(n=59)$} & \multicolumn{2}{|l|}{$-7 / 7 q-(n=38)$} & \multicolumn{2}{|l|}{ trisomy $8(n=44)$} \\
\hline Additional anomaly & Percent & Additional anomaly & Percent & Additional anomaly & Percent \\
\hline+8 & 17 & +21 & 10 & $5 q^{-}$ & 23 \\
\hline+21 & 13 & $5 q^{-}$ & 10 & +21 & 11 \\
\hline$-20 / 20 q-$ & 8 & +8 & 10 & $\operatorname{der}(3 q 21 / q 26)$ & 7 \\
\hline-7 & 7 & $\operatorname{inv}(3 q)$ & 5 & +11 & 7 \\
\hline $\operatorname{der} / \operatorname{del}(12 p)$ & 7 & $\operatorname{del}(12 p)$ & 5 & -7 & 5 \\
\hline $\operatorname{der} / \operatorname{del}(3 p)$ & 5 & $\mathrm{t}(11 \mathrm{q} 23)$ & 5 & $\operatorname{del}(12 p)$ & 5 \\
\hline $\operatorname{der} / t(21 q)$ & 5 & iso(17)(q10) & 5 & +13 & 5 \\
\hline $\mathrm{t}(11 \mathrm{q} 23)$ & 3 & Others & 50 & +14 & 5 \\
\hline \multirow[t]{3}{*}{ Others } & 35 & & & $+8^{*}$ & 5 \\
\hline & & & & $\operatorname{del}(1 p)$ & 5 \\
\hline & & & & Others & 22 \\
\hline
\end{tabular}


monosomy 7 even as an isolated abnormality confers a significantly bad prognosis. In our Austrian-German dataset, median survival times were 14 months for the isolated abnormality, 11 months for cases with one additional change, and 8 months for monosomy 7 as part of complex abnormalities (Fig. 3) [1].

Therapeutic options in the monosomy 7 subgroup are unsatisfying as yet. If age and clinical condition are adequate, patients should be treated with allogeneic stem cell transplantation whenever possible. Conventional intensive chemotherapy bears a high risk of early death and nonresponse. Even if a complete remission can be achieved, this frequently is of only short duration with a high risk of early relapse. In a recent report on 34 patients with MDS or AML treated with 5-azacytidine, the group of Mufti observed a preferentially good response of MDS patients with monosomy 7 to the demethylating agent 5-azacytidine. In this trial, five of the seven (71\%) complete responders had isolated chromosome 7 abnormalities and achieved a continuous complete remission (10 months follow-up) in contrast to patients with other karyotype abnormalities like trisomy 8 who relapsed within the first 6 months [36]. Supporting results have been recently published for the use of decitabine by Lübbert et al. [37]. Future multicentric therapy trials are needed to verify this observation in a higher number of patients.
Complex abnormalities

According to the International System for Human Cytogenic Nomenclature criteria, complex chromomosome abnormalities are defined by the simultaneous occurrence of at least three independent abnormalities within one cell clone [38]. This cytogenetic subtype is present in some $15 \%$ of all patients with MDS (roughly 30\% of all abnormal cases) and thus occurs in a frequency comparable to $5 \mathrm{q}$ deletions [1-3]. Complex abnormalities may be the result of a multistep process with sequential accumulation of abnormalities, called karyotype evolution. In some cases, karyotype evolution can be observed if repeated cytogenetic analyses are performed, unraveling the stepwise accumulation of secondary abnormalities with the starting point of a primary abnormality. In a few patients, cytogenetic analysis detects cell clones with primary and others with primary and secondary and possibly further abnormalities at one and the same time point. However, frequently, this process cannot be proven in the individual patient who presents with multiple chromosomal changes at first diagnosis. In most of these cases, complexity is profound with aberration numbers exceeding the threshold of three by far. Frequently, in these cases, cell-to-cell variations occur, and the chromosomal complement presents with a chaotic, mutator-like shape resembling cytogenetics of solid

Survival (Kaplan-Meier) of patients with -7/7q-

$-7 / 7 q-$ sole

$-7 / 7 q-$ with 1 additional aberration

$-7 / 7 q-$ within complex karyotype

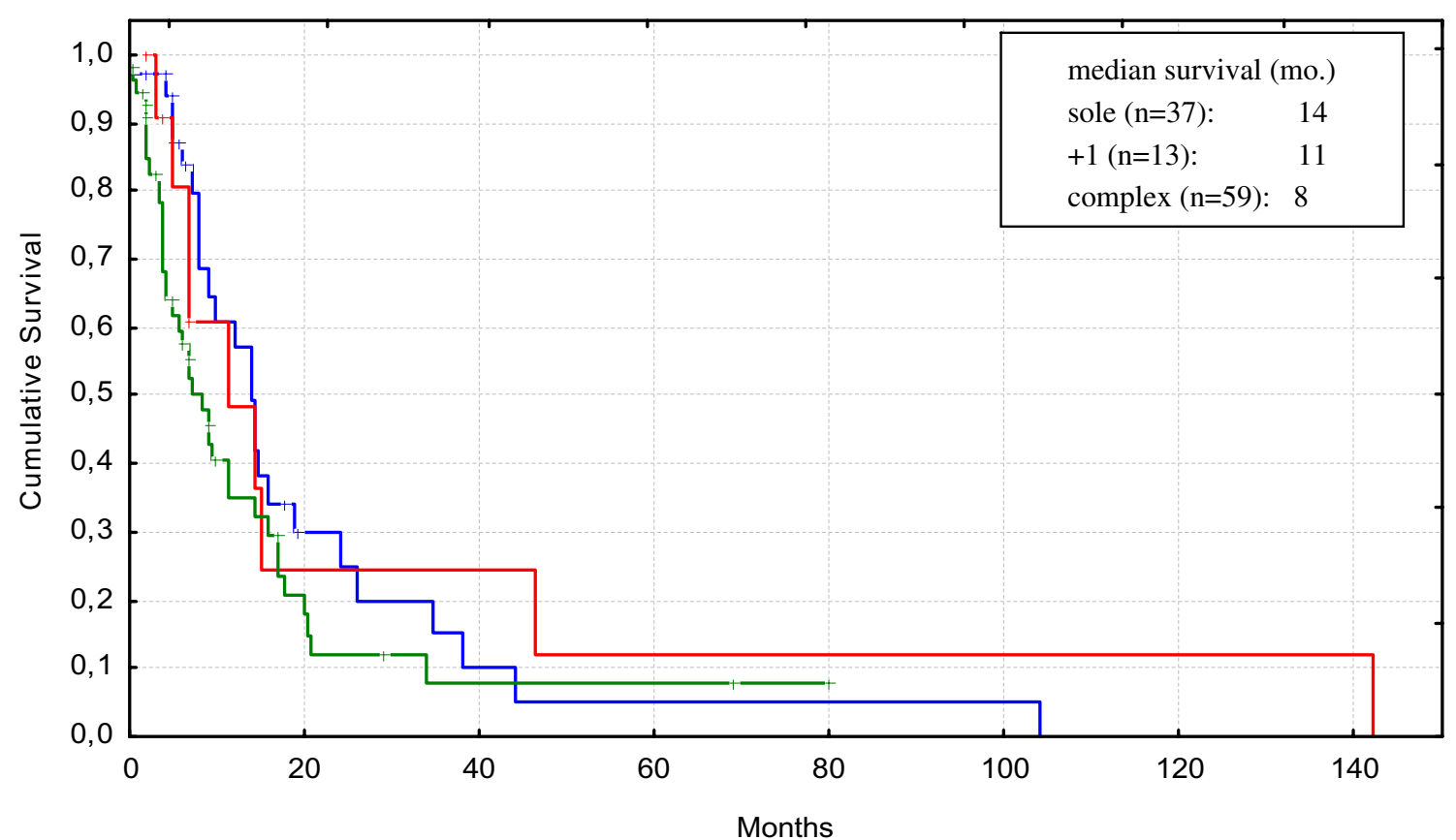

Fig. 3 Median survival according to accompanying abnormalities in patients with $-7 / 7 \mathrm{q}^{-}$. Log-rank test: $p=0.03$ ( 2 degrees of freedom), $p=0.94$ (isolated vs. +1$), p=0.07$ (isolated vs. complex), $p=0.43$ ( +1 vs. complex) 
tumors and malignancies in chromosomal breakage syndromes. Thus, it is conceivable that, in these cases, the process leading to complex abnormalities and genetic instability must proceed rapidly on the one hand and must involve mechanisms like DNA repair and cell cycle control comparable to the situation in DNA repair deficiency syndromes. Recent results of gene expression analyses in patients with MDS and complex chromosome abnormalities support these assumptions and are considered below in more detail [39]. In a substantial portion of patients with complex abnormalities, an exposition to therapeutically applied mutagens, like anthracyclines, topoisomerase II inhibitors, alkylating agents, and/or irradiation, can be traced in the medical history [40]. Within the subgroup of patients with complex changes, a broad range of the number of abnormalities with the majority of patients displaying greater than or equal to five chromosomal changes can be observed [39].

There is a strong association with unbalanced structural abnormalities affecting most frequently chromosomes $5 \mathrm{q}$ and 7q. Chromosomes less frequently involved in loss of genetic material were chromosomes 3 (p- and q-arms), 12p, $13 \mathrm{q}, 16 \mathrm{q}, 17 \mathrm{p}, 18 \mathrm{q}$, and 20q. Genomic gains were observed for chromosome 8/8q, 11q, and 21q [41]. Mutations of p53 have been observed in up to $90 \%$ of patients with AML and complex abnormalities [39]. Matrix comparative genomic hybridization $(\mathrm{CGH})$ analyses in patients with complex abnormalities revealed an association of complex karyotype changes with amplifications in the chromosomal regions 8q24, 9p24,,11q23, 12p13, 13q12, 20q11, and 2q1q22 [42].

Recently, characteristic profiles of complex abnormalities in AML were delineated by gene expression analyses. In this respect, a significant overexpression of RAD21, a double-strand-break DNA repair enzyme, as well as overexpression of other genes related to DNA-repair, apoptotic mechanisms, and cell-cycle control (RAD1, RAD 9A, RAD23B, RAD51AP1, NBS1, MSH6, SUMO1, and PARP2) was observed [39].

Taken together, these data might help to understand complex abnormalities as a maximum manifestation of genetic instability by allowing cells with significant DNA damages to circumvent physiologically protective apoptosis and to escape cytotoxicity of chemotherapy by intensified DNA repair. This model is also compatible with the high extent of chemo-resistance of hematopoietic cells with complex chromosome abnormalities, which is a wellknown and severe problem in the clinical management of high-risk MDS. Further clinical associations are the high median age of patients within this cytogenetic subgroup [43] and, related to conventional intensive chemotherapy, short remission durations and a high risk for early relapse [44]. Allogeneic stem cell transplantation, the only curative option for these patients, will only be feasible for a minority of individuals with complex chromosomal changes due to age-related multimorbidity and organ dysfunctions. New therapeutic strategies targeting hypermethylation, deacetylation, and immunomodulation, which have proven their tolerability also in aged patient populations, are now available for the treatment of patients with high-risk MDS. In this respect, two studies have to be mentioned. Cytogenetic responses in a substantial portion of patients with high-risk MDS have been observed in a multicentric study of decitabine, a potent demethylating agent. Major cytogenetic responses (MajCR) were observed in 38\% of 50 patients. Remarkably, 10 out of 26 patients $(38 \%)$ with high-risk cytogenetics displayed a MajCR; five of them had complex chromosome abnormalities. In the patients' group with MajCR, median survival time was 24 months as compared to the significantly shorter median survival time of 11 months in patients with persisting cytogenetic aberrations [45]. These observations are further supported by observations of our group. Within a cohort of 14 patients with high-risk MDS, we recently observed hematologic and cytogenetic responses to 5-azacytidine according to the modified International Working Group criteria [46] in three out of four patients with complex abnormalities [47].

Another new therapeutic mechanism, immunomodulation, might be effective in cases with complex karyotypic changes too. In this connection, a complete cytogenetic response to the immunomodulatory drug lenalidomide has been reported in patients with high-risk MDS with complex chromosome abnormalities harboring 5q deletions [48]. Further multicentric clinical trials are needed to confirm these observations.

\section{Conclusions}

In contrast to CML where the bcr-abl fusion forms the homogenous genetic basis of the disease [49], MDS show a profound heterogeneity, not only on the morphologic and clinical level but also on the genetic presentation. Three cytogenetic subgroups with prognostic relevance have been identified and were incorporated into prognostic scoring by the IPSS. However, in the great majority of cytogenetic changes, the prognostic relevance is still obscure. Genetic heterogeneity in MDS leads to the paradox situation that rare abnormalities can be observed frequently [1] with the consequence that, for a relevant portion of abnormalities, their prognostic impact is still unknown. The only chance to overcome these shortcomings is to establish multicentric cooperations, which are the goals of the German-Austrian MDS Study Group, which is now cooperating with the MD Anderson Cancer Centre as well as the IMRAW group [50-52]. New 
therapeutic strategies targeting immunomodulation and epigenetic changes proved to be of outstanding effectiveness and tolerability in comparison to established therapies not only for the low-risk $5 \mathrm{q}$ syndrome but also for high-risk MDS with as yet deleterious cytogenetic alterations like monosomy 7 and complex abnormalities.

However, what about the subgroup of nearly $50 \%$ of patients presenting with a normal karyotype? New techniques will help to further delineate the genetic background in these cases. Thus, very recently, two groups published their results of single nucleotide polymorphism analyses in MDS [53, 54]. The group of Mufti performed high-resolution single-nucleotide polymorphism (SNP) array analyses in 119 low-risk MDS patients of whom 32\% displayed clonal chromosome abnormalities to search for cryptic chromosomal aberrations not detectable by chromosomal banding analyses. They found uniparental disomy (UPD), a copy number neutral loss of heterozygosity, in $46 \%$ of patients, small deletions in $10 \%$, and amplifications in $8 \%$ of the cohort. The changes of copy numbers were acquired while UPDs were constitutional. The former aberrations were associated with a worsened outcome of the patients. The authors speculated that the high frequency of UPD may be indicative for a constitutional genomic instability in these patients [53]. This could be a predisposing factor for MDS. Maciejewski et al. applied $250 \mathrm{~K}$ SNP arrays to 94 patients with MDS and observed SNP aberrations in $75 \%$ of patients as compared to $59 \%$ clonal chromosomal abnormalities detected by metaphase analyses. Previously unknown lesions were found in patients with a normal-as well as in others with an abnormal-karyotype. In this study, UPD occurred in $20 \%$ of the MDS patients [54].

New analytical tools like matrix CGH, microarray gene expression analyses, proteomics, and methylation profiling will add substantially to the understanding of pathogenesis, delineation of therapeutic targets, and individualization of therapy in MDS.

Taken together cytogenetics is still the gold standard of genetic diagnosis in MDS providing "labels" like 5q-, monosomy 7 , or complex abnormalities for disease entities with a common biological behavior and clinical as well as prognostic impact. In the future, scientific progress will depend on the ability to combine established and newly developed methods to gain a comprehensive understanding of MDS, which will translate into an individualized and highly effective and well-tolerable treatment for all patients with MDS.

Open Access This article is distributed under the terms of the Creative Commons Attribution Noncommercial License which permits any noncommercial use, distribution, and reproduction in any medium, provided the original author(s) and source are credited.

\section{References}

1. Haase D, Germing U, Schanz J, Pfeilstocker M, Nosslinger T, Hildebrandt B, Kundgen A, Lubbert M, Kunzmann R, Giagounidis AA, Aul C, Trumper L, Krieger O, Stauder R, Muller TH, Wimazal F, Valent P, Fonatsch C, Steidl C (2007) New insights into the prognostic impact of the karyotype in MDS and correlation with subtypes: evidence from a core dataset of 2124 patients. Blood 110:4385-4395

2. Greenberg P, Cox C, LeBeau MM, Fenaux P, Morel P, Sanz G, Sanz M, Vallespi T, Hamblin T, Oscier D, Ohyashiki K, Toyama K, Aul C, Mufti G, Bennett J (1997) International scoring system for evaluating prognosis in myelodysplastic syndromes. Blood 89:2079-2088

3. Solé F, Luno E, Sanzo C, Espinet B, Sanz GF, Cervera J, Calasanz MJ, Cigudosa JC, Milla F, Ribera JM, Bureo E, Marquez ML, Arranz E, Florensa L (2005) Identification of novel cytogenetic markers with prognostic significance in a series of 968 patients with primary myelodysplastic syndromes. Haematologica 90:1168-1178

4. Knapp RH, Dewald GW, Pierre RV (1985) Cytogenetic studies in 174 consecutive patients with preleukemic or myelodysplastic syndromes. Mayo Clin Proc 60:507-516

5. Nowell PC, Besa EC, Stelmach T, Finan JB (1986) Chromosome studies in preleukemic states. Cancer 58:2571-2575

6. Nowell PC, Besa EC (1989) Prognostic significance of single chromosome abnormalities in preleukemic states. Cancer Genet Cytogenet 42:1-7

7. Billström R, Tiede $T$, Hansen S, Heim S, Kristoffersson U, Mandahl N, Mitelman F (1988) Bone marrow karyotype and prognosis in primary myelodysplastic syndromes. Eur J Haematol 41:341-346

8. Pierre RV, Catovsky D, Muft GJ, Swansbury GJ, Mecucci C, Dewald GW, Ruutu T, Van Den Berghe H, Rowley JD, Mitelman F, Reeves BR, Alimena G, Garson OM, Lawler SD, de La Chapelle A (1989) Clinical-cytogenetic correlations in myelodysplasia (preleukemia). Cancer Genet Cytogenet 40:149-161

9. Morel P, Hebbar M, Lai JL, Duhamel A, Preudhomme C, Wattel E, Bauters F, Fenaux P (1993) Cytogenetic analysis has strong independent prognostic value in de novo myelodysplastic syndromes and can be incorporated in a new scoring system: a report on 408 cases. Leukemia 7:1315-1323

10. Toyama K, Ohyashiki K, Yoshida Y, Abe T, Asano S, Hirai H, Hirashima K, Hotta T, Kuramoto A, Kuriya S, Miyazaki T, Kakishita E, Mizoguchi H, Okada M, Shirikawa S, Takaku F, Tomonaga M, Uchino H, Yasunaga K, Nomura T (1993) Clinical implications of chromosomal abnormalities in 401 patients with myelodysplastic syndromes: a multicentric study in Japan. Leukemia 7:499-508

11. Earle VL, Ross F, Fisher A, Strike P, Berrington S, Chieccho L, Cabanas ED, Washbourne R, Watts K, Grand T (2007) Haematopoietic growth factors significantly improve the mitotic index and chromosome quality in cytogenetic cultures of myeloid neoplasia. Genes Chromosomes Cancer 46:670-674

12. Malcovati L, Germing U, Kuendgen A, Della Porta MG, Pascutto C, Invernizzi T, Giagounidis A, Hildebrandt B, Bernasconi P, Knipp S, Strupp C, Lazzarino M, Aul C, Cazzola M (2007) Timedependent prognostic scoring system for predicting survival and leukemic evolution in myelodysplastic syndromes. J Clin Oncol 25:3503-3510

13. Germing U, Hildebrandt B, Pfeilstöcker M, Nösslinger T, Valent $P$, Fonatsch C, Lübbert M, Haase D, Steidl C, Krieger O, Stauder R, Giagounidis AA, Strupp C, Kündgen A, Mueller T, Haas R, Gattermann N, Aul C (2005) Refinement of the international prognostic scoring system (IPSS) by including LDH as an additional prognostic variable to improve risk assessment in patients with primary myelodysplastic syndromes (MDS). Leukemia 19:2223-2231 
14. White AD, Hoy TG, Jacobs A (1994) Extended cytogenetic follow-up and clinical progress in patients with myelodysplastic syndromes (MDS). Leuk Lymph 12:401-412

15. Haase D, Germing U, Schanz J, Pfeilstöcker M, Nösslinger T, Hildebrandt B, Kuendgen A, Lübbert M, Kunzmann R, Giagounidis A, Aul C, Trümper L, Krieger O, Stauder R, Müller T, Valent P, Fonatsch C, Steidl C (2006) New and comprehensive cytogenetic prognostication and categorization in MDS. Blood 108:252 (Abstract)

16. Grimwade D, Walker H, Oliver F, Wheatley K, Harrison C, Harrison G, Rees J, Hann I, Stevens R, Burnett A, Goldstone A (1998) The importance of diagnostic cytogenetics on outcome in AML: analysis of 1,612 patients entered into the MRC AML 10 trial. The medical research council adult and children's leukaemia working parties. Blood 92:2322-2333

17. Steidl C, Schanz J, Pfeilstöcker M, Nösslinger T, Hildebrandt B, Kündgen A, Lübbert M, Kunzmann R, Giagounidis A, Aul C, Trümper L, Krieger O, Stauder R, Müller TH, Wimazal F, Valent P, Fonatsch C, Germing U, Haase D (2007) Growing evidence for an underestimation of poor-risk cytogenetics in the international prognostic scoring system in myelodysplastic syndromes. Clin Leukemia 6:353-356

18. Nagarajan L (1995) Molecular anatomy of the 5q- chromosome. Leuk Lymphoma 17:361-366

19. Boultwood J, Fidler C, Strickson AJ, Watkins F, Gama S, Kearney L, Tosi S, Kasprzyk A, Cheng J-F, Jaju RJ, Wainscoat JS (2002) Narrowing and genomic annotation of the commonly deleted region of the $5 \mathrm{q}-$ syndrome. Blood 99:4638-4641

20. Olney HJ, LeBeau MM (2002) The myelodysplastic syndromes. Pathobiology and clinical management. In: Bennett JM (ed) The cytogenetics and molecular biology of myelodysplastic syndromes. Marcel Dekker, New York, pp 89-119

21. Pellagatti A, Cazzola M, Giagounidis AAN, Malcovati L, Della Porta MG, Killick S, Campbell LJ, Wang L, Langford CF, Fidler C, Oscier D, Aul C, Wainscoat JS, Boultwood J (2006) Gene expression profiles of $\mathrm{CD} 34^{+}$cells in myelodysplastic syndromes: involvement of interferon-stimulated genes and correlation to FAB subtype and karyotype. Blood 108:337-345

22. Ebert BL, Pretz J, Bosco J, Chang CY, Tamayo P, Galili N, Raza A, Root D, Attar E, Ellis SR, Golub TR (2008) Identification of RPS14 as the $5 \mathrm{q}$-syndrome gene by RNA interference screen. Nature 451:335-340

23. Van den Berghe H, Cassiman J-J, David G, Fryns J-P, Michaux JL, Sokal G (1974) Distinct hematological disorder with the deletion of long arm of no 5. chromosome. Nature 251:437-438

24. Giagounidis AAN, Germing U, Aul C (2006) Biological and prognostic significance of chromosome $5 \mathrm{q}$ deletions in myeloid malignancies. Clin Cancer Res 12:5-10

25. Giagounidis AAN, Haase S, Germing U, Schlegelberger B, Wilkens L, Büsche G, Kreipe HH, Wysk J, Grips K-H, Grabenhorst U, Rothmann F, Lübbert M, Ganser A, Aivado M, Heinsch M, Aul C (2005) Treatment of myelodysplastic syndrome with isolated del $(5 \mathrm{q})$ including bands $\mathrm{q} 31-\mathrm{q} 33$ with a combination of all-trans-retinoic acid and tocopherol-a: a phase II study. Ann Hematol 84:1432-1584

26. List A, Kurtin S, Roe DJ, Buresh A, Mahadevan D, Fuchs D, Rimsza L, Heaton R, Knight R, eldis JB (2005) Efficacy of lenalidomide in myelodysplastic syndromes. New Engl J Med 352:549-557

27. List A, Dewald G, Bennet J, Giagounidis A, Raza A, Feldman E, Powell B, Greenberg P, Thomas D, Stone R, Reeder C, Wride K, Patin J, Schmidt M, Zeldis J, Knight R, Myelodysplastic Syndrome-003 study investigators (2006) Lenalidomide in the myelodysplastic syndrome with chromosome $5 \mathrm{q}$ deletion. New Engl J Med 355:1456-1465

28. Liang H, Fairman J, Claxton DF, Nowell PC, Green ED, Nagarajan L (1998) Molecular anatomy of chromosome 7q deletions in myeloid neoplasms: evidence for multiple critical loci. Proc Natl Acad Sci USA 95:3781-3785

29. Tosi S, Scherer SW, Giudici G, Czepulkowski B, Biondi A, Kearney L (1999) Delineation of multiple deleted regions in 7q in myeloid disorders. Genes Chromosomes Cancer 25:384-392

30. Christiansen DH, Andersen MK, Pedersen-Bjergaard J (2003) Methylation of p15INK4B is common, is associated with deletion of genes on chromosome arm $7 \mathrm{q}$ and predicts a poor prognosis in therapy-related myelodysplasia and acute myeloid leukemia. Leukemia 17:1813-1819

31. Christiansen DH, Andersen MK, Pedersen-Bjergaard J (2004) Mutations of AML1 are common in therapy-related myelodysplasia following therapy with alkylating agents and are significantly associated with deletion or loss of chromosome arm 7q and with subsequent leukemic transformation. Blood 104:1474-1481

32. Chen G, Zeng W, Miyazato et al (2004) Distinctive gene expression profiles of CD34 cells from patients with myelodysplastic syndrome characterized by specific chromosome abnormalities. Blood 104:4210-4218

33. Haase D, Fonatsch C (1990) Monosomy 7 provides a proliferative advantage for leukemic cells under incubation with GM-CSF in vitro. Blut 61:322-323

34. Sloand EM, Yong ASM, Ramkissoon S, Solomou E, Bruno TC, Kim S, Fuhrer M, Kajigaya S, Barrett AJ, Young NS (2006) Granulocyte colony-stimulating factor preferentially stimulates proliferation of monosomy 7 cells bearing the isoform IV receptor. Proc Natl Acad Sci USA 103:14483-14488

35. Imashuku S, Hibi S, Bessho F, Tsuchida M, Nakahata T, Miyzaki S, Tsukimoto I, Hamajima N, Pediatric AA Follow-up Study Group in Japan (2003) Detection of myelodysplastic syndrome/acute myeloid leukemia evolving from aplastic anemia in children, treated with recombinant human G-CSF. Haematologica 88:136-141

36. Raj K, John A, Ho A, Chronis C, Khan S, Samuel J, Pomplun S, Thomas NSB, Mufti GJ (2007) CDKN2B methylation status and isolated chromosome 7 abnormalities predict responses to treatment with 5-azacytidine. Leukemia 21:1937-1944

37. Rüter B, Wijermanns P, Claus R, Kunzmann R, Lübbert M (2007) Preferentially cytogenetic response to continuous intravenous lowdose decitabine (DAC) administration in myelodysplastic syndrome with monosomy 7. Blood 110:1080-1082

38. Mitelman F (1991) ISCN guidelines for cancer cytogenetics, supplement to an international system for human cytogenetic nomenclature. Karger, Basel, Switzerland

39. Schoch C, Kern W, Kohlmann A, Hiddemann W, Schnittger S, Haferlach T (2005) Acute myeloid leukemia with a complex aberrant karyotype is a distinct biological entity characterized by genomic imbalances and a specific gene expression profile. Genes Chromosomes Cancer 43:227-38

40. Pedersen-Bjergaard J, Andersen MK, Christiansen DH, Nerlov C (2002) Genetic pathways in therapy-related myelodysplasia and acute myeloid leukemia. Blood 99:1909-1912

41. Trost D, Hildebrandt B, Beier M, Müller N, Germing U, Royer-Pokora B (2006) Molecular cytogenetic profiling of complex karyotypes in primary myelodysplastic syndromes and acute myeloid leukemia. Cancer Genet Cytogenet 165:51-63

42. Rücker FG, Bullinger L, Schwaenen C, Lipka DB, Wessendorf S, Fröhling S, Bentz M, Miller S, Scholl C, Schlenk RF, Radlwimmer B, Kestler HA, Pollack JR, Lichter P, Döhner K, Döhner H (2006) Disclosure of candidate genes in acute myeloid leukemia with complex karyotypes using microarray-based molecular characterization. J Clin Oncol 24:3887-3894

43. Bacher U, Kern W, Schnittger S, Hiddemann W, Haferlach T, Schoch C (2005) Population-based age-specific incidences of cytogenetic subgroups of acute myeloid leukemia. Haematologica 90:1502-1510

44. Knipp S, Hildebrandt B, Kündgen A, Giagounidis A, Kobbe G, Haas R, Aul C, Gattermann N, Germing U (2007) Intensive 
chemotherapy is not recommended for patients aged $\geq 60$ years who have myelodysplastic syndromes or acute myeloid leukemia with high-risk karyotypes. Cancer 25:3503-3510

45. Lübbert M, Wijermanns P, Kunzmann R, Verhoef G, Bosly A, Ravoet C, Andre M, Ferrant A (2001) Cytogenetic responses in high-risk myelodysplastic syndrome following low-dose treatment with the DNA methylation inhibitor 5-aza-2ф-deoxycytidine. Br J Haematol 114:349-35

46. Cheson BD, Greenberg PL, Bennett JM, Lowenberg B, Wijermans PW, Nimer SD, Pinto A, Beran M, de Witte TM, Stone RM, Mittelman M, Sanz GF, Gore SD, Schiffer CA, Kantarjian H (2006) Clinical application and proposal for modification of the International Working Group (IWG) response criteria in myelodysplasia. Blood 108:419-425

47. Braulke F, Schanz J, Steidl C, Truemper LH, Haase D (2007) FISH-analyses of circulating CD34+ cells in MDS-patients-a suitable method to measure and predict response to 5-Azacytidine. Blood 110:2466 (ASH Annual Meeting Abstracts)

48. Giagounidis AAN, Germing U, Strupp C, Hildebrandt B, Heinsch M, Aul C (2005) Prognosis of patients with del(5q) and complex karyotype and the possible role of lenalidomide in this patient subgroup. Ann Hematol 84:569-571

49. Sawyers CL (1999) Chronic myeloid leukemia. New Engl J Med $340: 1330-1340$
50. Haase D, Estey EH, Steidl C, Germing U, Garcia-Manero G, Kantarjian HM, Schanz J (2007) Multivariate evaluation of the prognostic and therapeutic relevance of cytogenetics in a merged European-American Cohort of 3860 patients with MDS. Blood 110:247 (ASH Annual Meeting Abstracts)

51. Schanz J, Estey EH, Steidl C, Germing U, Hildebrandt B, Garcia-Manero G, Kantarjian HM, Haase D (2007) Multivariate analysis suggests that the prognostic impact of poor cytogenetics is potentially underestimated in the IPSS. Blood 110:248 (ASH Annual Meeting Abstracts)

52. Steidl C, Schanz J, Le Beau MM, Bennett JM, Germing U, Greenberg PL, Haase D (2007) Coalescence of the German-Austrian and IMRAW Cytogenetic MDS databases: modification of patient risk groups. Blood 110:2468 (ASH Annual Meeting Abstracts)

53. Mohamedali A, Gäken J, Twine NA, Ingram W, Westwood N, Lea NC, Hayden J, Donaldson N, Aul C, Gattermann N, Giagounidis A, Germing U, List AF, Mufti GJ (2007) Prevalence and prognostic significance of allelic imbalance by single-nucleotide polymorphism analysis in low-risk myelodysplastic syndromes. Blood 110:3365-3373

54. Gondek LP, Tiu R, O'Keefe, Sekeres MA, Theil KS, Maciejewski JP (2008) Chromosomal lesions and uniparental disomy detected by SNP arrays in MDS, MDS/MPD and MDS-derived AML. Blood 111:1534-1542 